\title{
Waist circumference as high blood pressure predictor in school age children
}

\author{
Circunferência da cintura como preditora da pressão arterial \\ elevada em escolares
}

Nilcemar Rodrigues Carvalho Cruz (http://orcid.org/0000-0003-0820-6604) ${ }^{1}$
Pollyanna Costa Cardoso (http://orcid.org/0000-0002-2779-2912) ${ }^{1}$
Thaisa Netto Souza Valente Frossard (http://orcid.org/0000-0002-5708-7325) ${ }^{1}$
Fernanda de Oliveira Ferreira (http://orcid.org/0000-0002-5857-2824) ${ }^{1}$
Stela Brener (http://orcid.org/0000-0002-9294-1902) ${ }^{2}$
Antônio Frederico de Freitas Gomides (http://orcid.org/0000-0001-5540-2734) ${ }^{1}$
Maria Anete Santana Valente (http://orcid.org/0000-0002-8914-0493) ${ }^{1}$
Cibele Velloso-Rodrigues (http://orcid.org/0000-0002-4998-1765) ${ }^{1}$
${ }^{1}$ Universidade Federal de Juiz de Fora. R. José de Tassis 350, Vila Bretas. 35030-250 Governador Valadares MG Brasil. nilcemar.cruz@ufjf.edu.br

${ }^{2}$ Fundação e Centro de Hemoterapia e Hematologia de Minas Gerais. Belo Horizonte MG Brasil.

\begin{abstract}
Childhood hypertension is becoming more common with the increasing numbers of child obesity, which has encouraged new studies to identify a good anthropometric marker for high blood pressure levels. The objective this study was to identify the best anthropometric predictor of risk of hypertension in children between 8-10 years of age. The Children were evaluated for socioeconomic status and their blood pressure (BP), weight, height, waist circumference (WC) and percentage of body fat (PBF) were measured. The study included 445 children, of which $50.1 \%$ were females. The prevalence of obesity defined by body mass index (BMI) was $14.6 \%$. Increased BP was found in $3.4 \%$ and $2.2 \%$ of the children, considering the pre-hypertension and hypertension classifications respectively. The arithmetic mean of $B P$ value correlated significantly with $B M I, W C$ and PBF. After height control, the correlations that were maintained significant were between $W C$ and systolic blood pressure (SBP) and between WC and diastolic blood pressure (DBP). The variable with the highest predictive power of the occurrence of hypertension was WC. The results indicate that, in this population of children between 8 and 10 years old, WC is a measurement of higher value in predicting increased $B P$.

Key words Hypertension, Pediatric obesity, Body composition, Children
\end{abstract}

Resumo A hipertensão na infância está aumentando com a epidemia de obesidade infantil, o que tem incentivado estudos para identificar um bom marcador antropométrico dos níveis pressóricos aumentados. O objetivo do presente estudo foi identificar o melhor preditor antropométrico de risco de hipertensão arterial em crianças entre 8 e 10 anos de idade. Foi realizada avaliação socioeconômica e aferidos pressão arterial (PA), peso, estatura, circunferência da cintura (CC) e percentual de gordura corporal (\%GC). Das 445 crianças que participaram do estudo, 50,1\% eram do sexo feminino. A prevalência de obesidade definida pelo indice de massa corporal (IMC) foi 14,6\%. A PA aumentada foi observada em 3,4\% e 2,2\% das crianças, considerando as classificações pré-hipertensão e hipertensão, respectivamente. As médias dos valores pressóricos correlacionaram-se significativamente com IMC, CC, e \%GC $e$, após o controle da estatura, as correlações que se mantiveram significativas foram entre CC $e$ pressão arterial sistólica (PAS) e CC e pressão arterial diastólica (PAD). A variável que apresentou maior poder preditivo da ocorrência de hipertensão foi a CC. Os resultados indicam que na população estudada de crianças entre 8 e 10 anos de idade a CC é uma medida de valor superior para predizer PA aumentada.

Palavras-chave Hipertensão, Obesidade pediátrica, Composição corporal, Crianças 


\section{Introduction}

Blood pressure (BP) in childhood is a predictor of hypertension in later life, increases the risk for cardiovascular morbidity and mortality, and is associated with overweight ${ }^{1}$.

The latest figures estimate that between 42.5 and 51.8 million children and adolescents (019 years) in Latin America are overweight or obese, which represents 20 to $25 \%$ of this population. The prevalence of overweight in children of school age (5-11 years) ranged from 18.9 to $36.9 \%$ and it is estimated that 22.2 to 25.9 millions these children are overweight or obese ${ }^{2}$. Data from the of the Brazilian Institute of Geography and Statistics indicate that $1 / 3$ of Brazilian children between 5 and 9 years old were diagnosed with overweight ${ }^{3}$. At the same time, high $\mathrm{BP}$ in childhood has increased with the epidemic of childhood obesity ${ }^{4}$ reaching a prevalence of almost $5 \%$ of children and adolescents ${ }^{5}$.

Taking into account the relation between overweight and BP disorders, some studies have been investigating the association between a variety of anthropometric parameters and $\mathrm{BP}$ levels. These studies aim to identify a more suitable predictor for high BP in childhood and/or adolescence $^{6-9}$. Association between SBP and/or DBP and the waist-to-height ratio was observed among a sample of 3 to 4 years old children ${ }^{6}$. In another study, SBP and/or DBP were found to be associated with body mass index (BMI) and waist circumference (WC) among 3 to 6 years old children $^{8}$. In works that included in the study sample 7 to 10 years old children, association between the pressure levels and $\mathrm{WC}^{7,9}, \mathrm{BMI}$ and waist-tohip ratio ${ }^{7}$ as well as triceps and subscapular skinfolds ${ }^{9}$ were found.

It is known that, in addition to excess weight, increased WC is a risk factor for metabolic complications in adulthood. In children, WC was referenced be a good marker to investigate metabolic disorders, including hypertension in different age group ${ }^{10-13}$, however, the evidence of the WC as predictor for BP disorder among children is still limited. In this context, studies investigating the relationship of overweight/obesity and excessive abdominal fat with elevated BP in children, as performed by Choy et al. ${ }^{4}$, Colín-Ramírez et al. ${ }^{1}$, Flores-Huerta et al. ${ }^{14}$, are necessary, given its screening of potential hypertension, preventive health, and because it is an investigation still insufficiently explored and reported in children.

Our study evaluated the prevalence of excess weight and variations in BP measurements in children aged between 8 and 10, who attend public and private schools in a Brazilian city. In order to identify the best anthropometric predictor of the hypertension risk in childhood, this work also evaluates the association of BP levels with the following anthropometric variables: BMI, $\mathrm{WC}$ and percentage of total body fat (PBF).

\section{Methods and materials}

\section{Sample}

The study was conducted with children aged 8 to 10 years old enrolled in four public schools and three private schools of the city of Governador Valadares, Minas Gerais, Brazil, from May to August 2015. The sample size was calculated for prevalence studies, considering the prevalence of both obesity and hypertension in childhood from estimated data on epidemiological study conducted with a population of Brazilian children $^{3,15}$. It was stipulated $95 \%$ confidence, $4 \%$ estimation error and a design effect of 1.2, since sampling was conducted in a double stage (first we randomly selected a school and then a class). The minimum sample size of 347 participants has been found and $10 \%$ was add to this number in order to offset any losses that may occur during data collection, resulting in a total of 381 children.

To ensure the representativeness of the sample, we used the stratified proportional sampling technique selecting proportionally children according to the proportion of enrollments in Governador Valadares city (68\% of public schools and $32 \%$ of private schools). Uniform sampling was performed by age group, selecting the same number of children aged 8,9 and 10 years. To respect the uniform distribution by age and proportion by type of schools, it was decided that it would be necessary to select at least 127 children in each age group, with 102 public schools and 25 private schools. A pilot study involving 60 children was conducted aiming to test instruments and evaluation procedures.

\section{Ethical concerns}

The study protocol was approved by the ethics committee from Federal University of Juiz de Fora. Furthermore, written informed consent was obtained from parents or legal guardians, and the child's interest in participating in the study was asked before the measures. The study 
was conducted in accordance with the guidelines of the Declaration of Helsinki.

The following inclusion criteria was used: absence of chronic disease or inadequate conditions for anthropometry, such as the use of prosthesis, orthopedic cast, physical or neurological disability.

\section{Socioeconomic assessment}

For socioeconomic assessment was sent to the participant's home a questionnaire to be completed by parents of participating children, in which they informed the monthly family income and the mother's educational level.

Subjective options for family income assessment were presented. Subjects family income was grouped into three categories: 1 - up to three Brazilian minimum wage (MW), 2- between three and five minimum wages, 3- greater than five minimum wages. Subjects mothers education was grouped into 3 categories: 1- never studied, incomplete or complete elementary education, 2 - incomplete or complete secondary education, 3 - incomplete or complete undergraduate or postgraduate education.

\section{Anthropometric, Body Composition and Blood Pressure Evaluation}

The sex and birth date of the evaluated children were previously obtained from the school records.

The evaluations were carried out at the school on a previously scheduled day during school hours and after a minimum rest period of 5 minutes before evaluation. During the rest, were collected personal data and evaluated by the researcher the skin color (black, white, brown, yellow, indigenous).

For the anthropometric evaluations, measurements of weight, height and WC were taken. Tanita BC $558^{\circ}$ (Tanita Corporation of America, Arlington Heights, IL, USA) was used for weight measurement with $0.1 \mathrm{~kg}$ precision and height was measured with a portable Stadiometer Alturexata ${ }^{\circledR}$ with scale in millimeters. The measurements were taken with the child wearing light clothes, barefoot, positioned upright and erect, and with arms outstretched along the body. BMI was calculated by dividing weight by height squared $\left(\mathrm{kg} / \mathrm{m}^{2}\right)$. We calculated the Z-score of BMI (EZBMI) and height (EZH), according to sex and age, using the World Health Organization's international standard of child and adoles- cents growth ${ }^{16}$, by Anthroplus software. Children were considered overweight with BMI for age $>$ score $\mathrm{z}+1$ and $\leq$ score $\mathrm{z}+2$; obese $>$ score $\mathrm{z}+2$. Low stature was considered score $\mathrm{z}<-2$.

WC was measured to the level of the midpoint between lower margin of the last palpable rib and top of the iliac crest, using a non-elastic anthropometric measuring tape with an accuracy of $1 \mathrm{~mm}$. It was used the reference proposed by Taylor et al. ${ }^{17}$, by using the 80 th percentile for the excess abdominal fat classification.

The PBF was obtained by Tanita ${ }^{\circledR}$, Ironman model, four-pole. The children were kept upright, with minimum clothing. They informed data of sex and birth date. It was considered excess body fat values of 30\% and 25\% for girls and boys, respectively.

For the BP evaluation we followed the proposal of the National High Blood Pressure Education Program ${ }^{18}$. BP was measured using an aneroid sphygmomanometer, and selected the appropriate cuff for arm circumference. BP was measured in the right arm, with the child sitting and quiet, after a rest of at least 5 minutes, it was performed two measurements of at least one minute of difference between each measure to prevent venous congestion and maintain variability PA to a minimum. Thus, prehypertension and hypertension was defined as systolic blood pressure (SBP) and diastolic blood pressure (DBP) were greater than or equal to 90 and 95 percentiles for age, sex and height, respectively.

\section{Statistical analysis}

Descriptive analyzes were performed of socioeconomic, anthropometric, body composition and BP variables.

Categorical variables PBF, WC, EZBMI and BP were individually associated with income and education, using the chi-square test. The normality of the data was verified using the Kolmogorov-Smirnov test.

Pearson correlation analyzes were conducted to verify the intensity and direction of the relationship between the values of SBP and DBP, and anthropometric variables and body composition (EZBMI, WC, and PBF). Partial correlation was made between the SBP and DBP and waist circumference, controlling the effect of stature, not to be a bias.

To investigate which variable showed greater predictive value of high blood pressure, was conducted a multinomial logistic regression analysis. This analysis was conducted considering as de- 
pendent variable the presence of prehypertension and hypertension, separated into three groups: hypertension, prehypertension and normotensive, considering the latter as a reference for comparison with the other groups. The independent variables were EZBMI, WC, and PBF.

In order to investigate which variable would be more predictive of BP changes, the groups of hypertensive and pre-hypertensive children were separated and an analysis of binary logistic regression was conducted. This regression was performed using the conditional method, remaining in the model only those variables that remained significant. The independent variables included in the model were EZBMI, WC and PBF.

\section{Results}

The study was carried out in four public schools and three private schools. Initially 455 children from public schools and 141 from private schools were invited. However, 142 children were not included in the study because they did not have parental consent, three because they had neurological deficits and six children were not interested in participating. The final sample was 445 children, of which $313(70.3 \%)$ were children from public schools and 132 (29.7\%) from private.

Overall, the prevalence of overweight and obesity (including severe obesity) defined by the EZBMI was $21.3 \%$ and $14.6 \%$, respectively. As for the estimation of PBF, $24 \%$ of children had excess body fat. The WC was considered increased in $17.9 \%$ of the students. The low height and thinness showed low prevalence $(0.2 \%$ and $1.3 \%$, respectively).

The average SBP was $94.2 \mathrm{mmHg}$ ( $\mathrm{SD}=6.42$ $\mathrm{mmHg})$ and $\mathrm{DBP}$ was $57.6 \mathrm{mmHg}(\mathrm{SD}=5.94$ $\mathrm{mmHg}$ ). SBP and / or increased DBP was observed in $3.4 \%$ and $2.2 \%$ of children given the pre-hypertension and hypertension rankings, respectively.

Of the total sample, $242(54.4 \%)$ were brown, $139(31.2 \%)$ white, 61 black (13.7\%) and 3 $(0.7 \%)$ did not inform skin color. The prevalence of hypertension was 3,3\% in brown children, $1,6 \%$ in black children and $0,7 \%$ in white children. The occurrence of pré-hypertesion was $3,7 \%$ in the brown children, $3,6 \%$ in the white children and $16 \%$ in the black children, No significance differences were found in the prevalence of hypertension in black, brown or white children $(\mathrm{p}=0,480)$.

Of the total number of children evaluated in schools, 221 parents or guardians, $(49.6 \%)$ filled the socioeconomic questionnaire. Among the mothers who answered the questionnaire $36.6 \%$ have never attended school or, at most, have completed primary education; $45,7 \%$ have attended or completed high school level. The family income data showed that $76 \%$ of respondents received a value lower than $3 \mathrm{MW}, 12,2 \%$ received from 3 to $5 \mathrm{MW}$ and 11,8 received more than $5 \mathrm{MW}$. Of the total number of children who presented BP variation $63.6 \%$ had a monthly income of less than $3 \mathrm{MW}$. There was no significant association between BP and income $(\mathrm{p}=0,347)$ or education $(\mathrm{p}=208)$.

The mean SBP and DBP were significantly correlated with EZBMI, WC and PBF. The values found in correlation analysis are shown in Table 1. Considering the possible influence of height in WC it was performed a partial correlation between WC and BP by controlling the effect of height, which revealed that the correlations remained significant between WC and SBP $(r=$ $0.189, \mathrm{p}<0.001)$ and WC and DBP $(\mathrm{r}=0.221$, $\mathrm{p}<0.001$ ). A significant correlation was found, using the chi-square test, between hypertension (yes vs. no) and WC (p $<0.001)$.

The multinomial logistic regression analysis revealed that, considering jointly the effect of EZBMI, WC, and PBF, the variable with the predictive power of the occurrence of hypertension was the WC, and every centimeter over WC, elevated in 1.22 times the chance of the child being hypertensive (Table 2).

The variable that remained significant in binary regression model was WC, indicating that this variable was the most predictive of the occurrence of BP disturbances (Table 3).

\section{Discussion}

The high prevalence of overweight and obesity in children is observed in several studies ${ }^{10,19-23}$. A survey from 2008 to 2009 by the Brazilian Institute of Geography and Statistics showed that the prevalence of overweight among Brazilian children aged 5-9 years increased from about $13.4 \%$ in 1989 to $33.4 \%$ in 2008 . For the same period, obesity increased from $3.2 \%$ to $14.2 \%$, reaching a prevalence of $13.6 \%$ and $12.2 \%$ in children aged 8 and 9 years old, respectively ${ }^{3}$. These results are close to the one found in this study $(14.6 \%$ of obese children). The results of the present study also match others national studies of school population, public and private school networks, which found prevalence of obesity of $12.4 \%{ }^{24}$ and $13.7 \%{ }^{25}$. This scenario indicates concern as 
Table 2. Multinomial logistic regression considering blood pressure classification (Hypertension, prehypertension or normotension) as dependent variable.

\begin{tabular}{lcccc}
\hline & OR & \multicolumn{2}{c}{ 95\% CI } & P-value \\
\cline { 1 - 3 } Prehypertension * & & Inferior limit & Upper limit & \\
EZBMI & 1.912 & 0.76 & 4.807 & 0.16 \\
WC & 0.991 & 0.876 & 1.121 & 0.89 \\
PBF & 0.981 & 0.846 & 1.139 & 0.80 \\
Hypertension * & & & \\
EZBMI & 0.503 & 0.163 & 1.558 & 0.23 \\
WC & 1.221 & 1.032 & 1.444 & $0.02^{\star}$ \\
PBF & 0.999 & 0.837 & 1.191 & 0.98 \\
\hline Reference: normotension
\end{tabular}

Table 3. Binary logistic conditional regression considering blood pressure alteration as dependent variable and waist circumference as independent variable.

\begin{tabular}{cccc}
\hline & OR & $95 \%$ CI & p-value \\
\hline WC & $1.008^{\star}$ & $1.041-1.1137$ & $<0.001$ \\
\hline
\end{tabular}

${ }^{*}$ Adjusted for the variables body mass index and percentage of body fat. WC: waist circumference.

some evidence correlate childhood obesity with metabolic and cardiometabolic risk factors in adulthood $^{26}$, or as early as possible, even during childhood $^{27,28}$, are a key determinant of BP in children and adolescents ${ }^{29}$.

The WC is considered a central adiposity marker ${ }^{30}$ being also recommended as an indicator of total body fat ${ }^{31}$. In a study with 680 children aged 7 to 11 years from a public school, Mazaro et al. ${ }^{32}$ reported increased WC values (15.4\%), number similar to the one found in the present work (17.9\%). Melzer et al..$^{33}$ verified by WC measurement that, in their home-based study with 357 families of children aged 3 to 10 , $30.5 \%$ of the children had abdominal fat accumulation and that it was associated with the nu- tritional status of the child. Increased abdominal fat was also observed in $13.4 \%$ of 1408 children aged 5-10 who were enrolled in public school ${ }^{34}$ and in $9.3 \%$ of the 1253 students aged 7 to 17 from public and private schools ${ }^{25}$.

More recently, studies have been trying to determine, between anthropometric parameters, which is the best marker of metabolic abnormalities ${ }^{26-28,35}$. Damasceno et al..$^{36}$ affirmed that there are indications of a significant association between the classification of children for EZBMI and WC, the correlation coefficient between the two measures is considered strong.

In the case of BP disturbances, several studies have investigated associations between anthropometric variables with BP in children in different age groups, and found increased risk of BP increase with increasing EZBMI ${ }^{5,15,19,28,29,37}$ and $\mathrm{WC}^{1,4,10,19,38}$.

The identification of the best anthropometric marker of increased BP in children becomes feasible as routine in clinical practice, whereas BP measurement in children is not part of a universal standard protocol as well as the considerable prevalence of hypertension among children with great variation depending on the degree of adiposity, age and ethnicity ${ }^{6,17,19,29}$.

This study found a prevalence of $3.4 \%$ and $2.2 \%$ of pre-hypertension and hypertension, re- 
spectively. These values are smaller than the values of $8.85 \%$ and $5.18 \%$ found by Reuter et al. ${ }^{24}$ in a study with 1950 Brazilian children and adolescents aged 7-18 years.

In this study, it was observed that both SBP and DBP correlated with BMI, WC and PBF. Notably, the variable WC was better correlated with increased blood pressure, being observed an increase of 1.22 times the chance of the child becoming hypertensive every centimeter increased in WC. Thus, an increase by five centimeters, for example, would present an increased chance for the child to become hypertensive of 6.1 times. Flores-Huerta et al. ${ }^{14}$ observed in 2029 Mexican children and adolescents that the prevalence and the likelihood of high blood pressure were higher in those with increased WC compared to high BMI. The positive association between WC and BP was also confirmed in other studies with children or adolescents. Mazaro et al. ${ }^{32}$ found increased BP values in $10.9 \%$ of the sample. They also observed association between elevated BP and increased WC. Souza et al. ${ }^{25}$ found high BP in $7.7 \%$ of the sample and a significant association of obesity, according to BMI and WC, with elevated BP. Burgos et al. ${ }^{7}$ found that WC correlated positively with BMI and BP.

Pooled data analysis of eight major epidemiological studies involving more than 47,000 children, found that regardless of race, gender and age, the risk of increased BP was significantly higher for those in the BMI top percentile compared with lower BMI percentile ${ }^{5}$. Although studies indicate a strong association between abdominal fat accumulation and overweight by BMI for age ${ }^{33}$, in this study the WC and EZBMI did not show the same association with the BP. The influence of WC in BP remained significant regardless of BMI. These results are consistent with previous studies in various populations who also noted that the WC was more sensitive to indicate risk of increased BP when compared to $\mathrm{BMI}^{1,4,14}$. It was suggested that one of the reasons that the WC identifies a greater number of children with elevated BP is better because it estimates the intra-abdominal fat, while BMI mainly estimates the total and subcutaneous $\mathrm{fat}^{14}$.

Evaluating Chinese children and adolescents 7-17 years of age, participants of the "National Surveys on Chinese Students' Constitution and Health", and analyzing those with normal BMI, it was found that Z-scores of SBP, DBP and the prevalence of high BP for boys and girls were significantly higher in the presence of abdominal obesity, defined by increased $\mathrm{WC}^{29}$. In fact, studies suggest that abdominal obesity should be considered a determining factor in the increase in BP and a major factor contributing to the increased prevalence of hypertension in children and adolescents ${ }^{40}$. The WC is associated with cardiovascular risk factors ${ }^{39}$ and it is a predictor of hypertension risk in children and adolescents $\mathrm{s}^{38}$.

These results indicate that children with normal weight, but with abdominal obesity should be screened for risk of high BP because alone, BMI may not provide sufficient sensitivity to identify risk of hypertension. Thus, the measurement of WC should be seen as an additional tool for analysis of BMI to help identify high BP among children. Kavey et al. ${ }^{5}$ point out that, since hypertension is an asymptomatic condition, the BP measurement should be routine for all health care for children starting from three years old.

Other factors not investigated in this study can be correlated to high BP in children. The higher sodium intake is correlated with increased SBP in Brazilian children aged 3-4 years ${ }^{6}$ and the high consumption of processed and ultra-processed foods justify this excessive sodium consumption as well as energy suggesting risk development of obesity and associated diseases ${ }^{40,41}$.

Whereas childhood obesity and involved co-morbidities, including high BP are the main health concerns worldwide ${ }^{42}$ and which often persists in future ages and causes serious consequences to health, more specifically to cardiovascular health, populational screening studies should be encouraged through the use of measuring WC, which features low cost, practicality and is easy to perform. This study suggests that in addition to BMI, is included to measure the WC and hypertension risk analysis in children. In addition, health promotion measures are necessary to encourage healthy eating and regular physical activity.

Limitations of this study include BP levels being obtained by a single visit. In addition, some potential factors of BP elevation, such as sodium intake, a positive family history and investigation of the presence of genotypic variation were not included. These factors will be considered in future studies. Our sample of children is representative of the children of eight to ten years, of both public and private schools of the Governador Valadares city, therefore not being representative of the Brazilian population.

The comparison of the results presented with other studies should be performed with caution as different references were used for WC analysis in populations of different ethnicities. Consider- 
ing the predictive value WC in increased BP risk assessment in children as well as the feasibility of its use, there is need for an international definition of abdominal obesity in children in order to standardize the assessment studies. According to Monzani et al. ${ }^{43}$, the cut-off point should be set according to the cardiometabolic risk to be used to identify children at high risk of cardiometabolic complications providing specific and immediate health interventions.

\section{Conclusion}

The results indicate that within the studied population of children between 8 and 10 years old, WC is a measurement of higher value in predicting increased BP. It can be considered that the results presented in this study may contribute to future decisions regarding the use of the measure of WC as a marker of increased BP levels, thus indicating individuals with higher risk and in need of a proper assessment of BP levels.

\section{Collaborations}

NRC Cruz participated in the design of the study, analysis and interpretation of the data, and in the final writing. PCC Pires helped with data collection, drafting and revising the paper. TNSV Frossard assisted the design of the study and data collection. FO Ferreira worked on data analysis and interpretation. S Brener participated in the delimitation of the study. AFF Gomides worked on the study design and delimitation, and in the closing revision. MAS Valente worked on the study design and delimitation. C Velloso-Rodrigues participated in the study design and delimitation, and in the final writing and revising.

\section{Acknowledgments}

The authors appreciate the cooperation of the Professors Ione Maria de Matos from Federal University of Juiz de Fora; we are grateful to the students who participated in the survey for their cooperation. We thank all participating families and school officials. We thank the Minas Gerais Research Foundation (FAPEMIG) and Financier of Studies and Projects (FINEP) by financial support.

This work and the postgraduate scholarship granted to Nilcemar Rodrigues Carvalho Cruz was supported by Minas Gerais Research Foundation (FAPEMIG); the Scientific Initiation scholarships were financed by Federal University of Juiz de Fora, some equipments were granted to Financier of Studies and Projects (FINEP). 


\section{References}

1. Colín-Ramírez E, Castillo-Martínez L, Orea-Tejeda A, Romero ARV, Castañeda AV, Lafuente EA. Waist circumference and fat intake are associated with high blood pressure in mexican children aged 8 to 10 years. J Am Diet Assoc 2009; 109(6):996-1003.

2. Rivera JA, Cossío TG, Pedraza LS, Aburto TC, Sánchez TG, Martorell R. Childhood and adolescent overweight and obesity in Latin America: a systematic review. Lancet Diabetes Endocrinol 2014; 2(4):321-332.

3. Brazilian Institute of Geography and Statistics (IBGE). 2008-2009 Household budget survey. Rio de Janeiro: IBGE; 2011. Portuguese

4. Choy C, Chan W, Chen T, Shih C, Wu L, Liao C. Waist circumference and risk of elevated blood pressure in children: a cross-sectional study. BMC Public Health 2011; 11:613

5. Kavey RW, Daniels SR, Flynn JT. Management of high blood pressure in children and adolescents. Cardiol Clin 2010; 28(4):597-607.

6. Vitolo MR, da Costa Louzada ML, Rauber F, Campagnolo PD. Risk factors for high blood pressure in low in come children aged 3-4 years. Eur J Pediatr 2013; 172(8):1097-1103.

7. Burgos MS, Burgos LT, Camargo MD, Franke SIR, Prá D, Silva AMV, Borges TS, Todendi PF, Reckziegel MB, Reuter CP . Relationship between anthropometric measures and cardiovascular risk Factors in children and adolescents. Arq Bras Cardiol 2013; 101(4):288296.

8. Gopinath B, Baur LA, Garnett S, Pfund N, Burlutsky G, Mitchell P. Body mass index and waist circumference are associated with blood pressure in preschool-aged children. Ann Epidemiol 2011; 21(5):351357.

9. Maffeis C, Pietrobelli A, Grezzani A, Provera S, Tato L. Waist circumference and cardiovascular risk factors in prepubertal children. Obes Res 2001; 9(3):179-187.

10. Dong B, Wang Z, Arnold LW, Yang Y, Ma J. Role of waist measures in addition to body mass index to assess the hypertension risk in children. Blood Press 2016; 25(6):344-350.

11. Maffeis CM, Banzato C, Talamini G. Waist-height ratio, a useful index to identify high metabolic risk in overweight children. J Pediatr 2008; 152(2):207-213.

12. Hirschler V, Aranda C, Calcagno ML, Maccalini G, Jadzinsky M. Can waist circumference identify children with the metabolic syndrome? Arch Pediatr Adolesc Med 2005; 159(8):740-744.

13. Sarria A, Moreno LA, Garcí -Liop LA, Fleta J, Morellón MP, Bueno M. Body mass index, triceps skinfold and waist circumference in screening for adiposity in male children and adolescents. Acta Paediatr 2001; 90(4):387-392.

14. Flores-Huerta S, Klunder-Klunder M, Reyes de la Cruz L, Santos JI. Increase in body mass index and waist circumference is associated with high blood pressure in children and adolescents in Mexico City. Arch Med Res 2009; 40(3):208-215.
15. Moraes LI, Nicola TC, Jesus JSA, Alves ERB, Giovaninni NPB, Marcato DG, Sampaio JD, Fuly JTB, Costalonga EF. High blood pressure in children and its correlation with three definitions of obesity in childhood. Arq Bras Cardiol 2014; 102(2):175-180.

16. de Onis M, Onyango A, Borghi E, Siyam A, Blössner $\mathrm{M}$, Lutter C. Worldwide implementation of the WHO Child Growth Standards. Public Health Nutr 2012; 15(09):1603-1610.

17. Taylor RW, Jones IE, Williams SM, Goulding A. Evaluation of waist circumference, waist-to-hip ration, and the conicity index as screening tools for high trunk fat mass, as measured by dual-energy X-ray absorptiometry, in children aged 3-19 y. Am J Clin Nutr 2000; 72(2):490-495.

18. National High Blood Pressure Education Program Working Groupon High Blood Pressure in Children and Adolescents. The Fourth Report on the diagnosis, evaluation, and treatment of high blood pressure in children and adolescents. Pediatrics 2004; 114(2 Supl. $4^{\text {th }}$ Report):555-576.

19. Álvarez C, Ramírez-Campillo R, Martínez-Salazar C, Vallejos-Rojas A, Jaramillo-Gallardo J, Bravo CS, Cano-Montoya J, Celis-Morales C. Hypertension in relation to nutritional status, physical activity and ethnicity in Chilean children aged 6 to 13. Nutr Hosp 2016; 33(2):220-225.

20. Rojo-Trejo ME, Peniche DBR, Jiménez MRA, Silva EFS. Body composition in children between 8 and 10 years of age, with a history of low birth weight in Querétaro, México. Nutr Hosp 2016; 33(3):544-548.

21. Afrifa-Anane E, Agyemang C, Codjoe SNA, Ogedegbe G, Aikins AG. The association of physical activity, body mass index and the blood pressure levels among urban poor youth in Accra, Ghana. BMC Public Health 2015; 15:269.

22. Niehues JR, Gonzales AI, Lemos RR, Bezerra PP, Haas P. Prevalence of overweight and obesity in children and adolescents from the age range of 2 to 19 years old in Brazil. Int J Pediatr 2014; 2014:583207.

23. Gopinath B, Baur LA, Garnett S, Pfund N, Burlutsky G, Mitchell P. Body mass index and waist circumference are associated with blood pressure in preschool-aged children. Ann Epidemiol 2011; 21(5):351-357.

24. Reuter CP, Burgos LT, Camargo MD, Possuelo LG, Reckziegel MB, Reuter EM, Meinhardt FP, Burgos MS. Prevalence of obesity and cardiovascular risk among children and adolescents in the municipality of Santa Cruz do Sul, Rio Grande do Sul. Med J 2013; 131(5):323-330.

25. Souza MGB, Rivera IR, Silva MAM, Carvalho ACC. Relationship of Obesity with High Blood Pressure in Children and Adolescents. Arq Bras Cardiol 2010; 94(6):714-719.

26. Faienza MF, Wang DQH, Garruti GFG, Portincasa P. The dangerous link between childhood and adulthood predictors of obesity and metabolic syndrome. Intern Emerg Med 2016; 11(2):175-182. 
27. Anderson LN, Lebovic G, Hamilton J, Hanley AJ, McCrindle BW, Maguire JL, Parkim PC, Birken CS, TARGet Kids collaboration. Body Mass Index, Waist circumference, and the clustering of cardiometabolic risk factors in early childhood. Paediatr Perinat Epidemiol 2016; 30(2):160-170.

28. Sardinha LB, Santos DA, Silva AM, Grøntved A, Andersen LB, Ekelund U. A comparison between BMI, waist circumference, and waist-to-height ratio for identifying cardio-metabolic risk in children and adolescents. Plos One 2016; 11(2):1-14.

29. Zhang Y, Zhang Z, Xie L. Distribution curve of waistto-height ratio and its association with blood pressure among children and adolescents: study in a large population in an eastern coastal province, China. Eur J Pediatr 2014; 173(7):879-885.

30. Ma J, Wang Z, Dong B, Song Y, Hu P, Zhang B. Body fat and blood pressure: comparison of blood pressure measurements in Chinese children with different body fat levels. Br J Nutr 2012; 108(9):1672-1677.

31. Ricardo GD, Caldeira GV, Corso ACT. Prevalence of overweight and obesity and central adiposity indexes among school-aged children in Santa Catarina, Brazil. Rev Bras Epidemiol 2009; 12(3):424-435.

32. Mazaro IAR, Zanolli ML, Antonio MARGM, Morcillo AM, Zambon MP. Obesity and cardiovascular risk factors in school children from Sorocaba, SP. Rev Assoc Med Bras 2011; 57(6):674-680.

33. Melzer MRTF, Magrini IM, Domene SMA, Martins PA. Factors associated with abdominal obesity in children. Rev Paul Pediatr 2015; 33(4):437-444.

34. Iampolsky MN, Souza FIS, Sarni ROS. Influence of body mass index and abdominal circumference on children's systemic blood pressure. Rev Paul Pediatr 2010; 28(2):181-187.

35. Zhu Y, Shao Z, Jing J, Ma J, Chen Y, Li X, Yang W, Guo $\mathrm{L}$, Jin Y. Body mass index is better than other anthropometric indices for identifying dyslipidemia in chinese children with obesity. Plos One 2016; 11(3):1-11.

36. Damasceno MMC, Fragoso LVC, Lima AKG, Lima ACS, Viana PCS. Correlation between body mass index and waist circumference in children. Acta Paul Enferm 2010; 23(5):652-657.

37. Marcovecchio ML, Mohn A, Diddi G, Polidori N, Chiarelli F, Fuiano N. Longitudinal assessment of Blood pressure in school-Aged Children: A 3-year follow-up study. Pediatr Cardiol 2016; 37(2):255-261.

38. Burgos MS, Burgos LT, Camargo MD, Franke SIR, Prá D, Silva AM, Borges TS, Todendi PF, Reckziegel MB, Reuter CP. Relationship between anthropometric measures and cardiovascular risk factors in children and adolescents. Arq Bras Cardiol 2013; 101(4):288-296.

39. Burgos MS, Reuter CP, Possuelo LG, Valim ARM, Renner JDP, Tornquist L, Torniquist D, Gaya AR. Obesity parameters as predictors of early development of cardiometabolic risk factors. Cien Saude Colet 2015; 20(8): 2381-2388.
40. Zhang YX, Wang SR. Comparison of blood pressure levels among children and adolescents with different body mass index and waist circumference: study in a large sample in Shandong, China. Eur J Nutr. 2014; 53(2):627-634.

41. Barcelos GT, Rauber F, Vitolo MR. Processed and ultra-processed food products and nutrient intake in children. Ciência \& Saúde 2014; 7(3):155-161.

42. Xi B, Shen Y, Zhao X, Chandak GR, Cheng H, Hou D, Li Y, Ott J, Zhang Y, Wang X, Mi J. Association of common variants in/near six genes (ATP2B1, CSK, MTHFR, CYP17A1, STK39 and FGF5) with blood pressure/hypertension risk in Chinese children. J Hum Hypertens 2014; 28(1):32-36.

43. Monzani A, Rapa A, Prodam F, Fuiano N, Diddi G, Petri A, Bellone S, Bona G. High discrepancy in abdominal obesity prevalence according to different waist circumference cut-offs and measurement methods in children: need for age-risk-weighted standardized cutOffs? Plos One 2016; 11(1):1-9.

Artigo apresentado em 13/03/2017

Aprovado em 14/08/2017

Versão final apresentada em 16/08/2017 
